María Jesús Torrens Álvarez

\title{
Los coordinadores disyuntivos latín et aut $>$ castellano (e)do $>$ vasco edo: una historia inadvertida*
}

\begin{abstract}
The relationship between the conjunctive coordinator 'and' and the disjunctive coordinator 'or' in natural languages constitutes the theoretical framework for this research, which examines its expression in Latin, medieval Castilian and Basque. The study reveals two disjunctive coordinators which have so far not been registered in literature on the subject, the Latin pleonasm et aut and the medieval Castilian $d o$, and we analyse their relationship with the Basque edo, still very much alive today, but whose origin has not so far found a satisfactory explanation. The theoretical arguments and empirical data allow us to defend the historical sequence - Latin et aut $>$ medieval Castilian (e)do $>$ Basque $e d o-$, and to focus attention on the problems posed by the conceptual dichotomies conjunction/disjunction and inclusive/exclusive disjunction for the description of semantic relationship contained under the term «coordination».
\end{abstract}

Keywords: Coordination, conjunction, disjunction, disjunctive coordinators, Latin, medieval Castilian, Basque

Coordinación conjuntiva, coordinación disyuntiva, coordinadores disyuntivos, latín, castellano medieval, euskera

Prof. Dr. María Jesús Torrens Álvarez: Consejo Superior de Investigaciones Científicas (CSIC), Instituto de Lengua, Literatura y Antropología, C/Albasanz, 26-28, E-28037 Madrid, E-Mail: mariajesus.torrens@cchs.csic.es

\section{Introducción}

En este artículo vamos a ocuparnos de dos coordinadores disyuntivos, uno latino y otro del castellano medieval, hasta ahora no recogidos en las gramáticas, y de la etimología de otro nexo disyuntivo del euskera cuyo origen no contaba por el momento con una explicación satisfactoria. El hallazgo del marcador do 'o' en documentos castellanos del siglo XIII del norte de Burgos ha sido el punto de partida de este estudio, en el que demostraremos la existencia del pleonasmo latino et

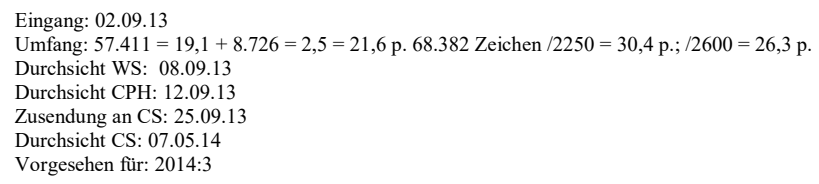


aut, tampoco recogido en la bibliografía, y estableceremos la relación de estos elementos con el vasco edo, que goza de una gran vitalidad hoy en día. Revisaremos brevemente la expresión de la disyunción en cada una de estas tres lenguas y las dependencias que entre las tres se establecen con el fin de argumentar la secuencia de hechos lingüísticos que se enuncia en el título del trabajo.

Para ello será preciso que busquemos en la teoría lingüística los fundamentos que nos permitan explicar la naturaleza de las relaciones lógico-semánticas que se engloban bajo el término «coordinación» y que están detrás de los procesos diacrónicos que aquí se describen. El análisis de su codificación en las tres lenguas nos permitirá, asimismo, cuestionar la idoneidad de algunos planteamientos teóricos aceptados de manera general, concretamente, las dicotomías conjunción / disyunción y, dentro de esta, inclusión / exclusión.

\section{La disyunción en las lenguas naturales}

De los tres tipos básicos de coordinación establecidos, la conjuntiva ('and'), la disyuntiva ('or') y la adversativa ('but'), nos vamos a ocupar de algunos aspectos de la disyuntiva y de su relación con la conjuntiva en oraciones declarativas, claves que expondremos brevemente y que constituirán el marco teórico de las propuestas etimológicas que aquí presentamos.

Para Mauri (2008, 295), las tres relaciones coordinantes, que denomina combination ('and'), contrast ('but') y alternative ('or'), no son equivalentes, sino que se organizan en una doble estructura jerárquica:

«Combination is the most basic and semantically unspecified linkage relation, for it is implied both by contrast and alternative. [...] Contrast and alternative are regarded as further specifications of the combination relation along two different and separate semantic directions: contrast is a combination specified on the basis of a conflicting discontinuity between the SoAs (states of affairs ${ }^{1}$ ), whereas alternative is a combination specified on the basis of the irreality and replaceability of the linked SoAs».

Ciñéndonos a 'and' y 'or', la disyunción es, sin duda, mucho menos prominente en las lenguas naturales que la conjunción, ${ }^{2}$ hasta el punto de que numerosas lenguas que tienen palabras para expresar 'and' carecen de formas específicas para 'or' (Ohori 2004, 56-59). Que en el discurso los elementos 'and' sean mucho más frecuentes que los 'or' a su vez explica que en muchas lenguas los

\footnotetext{
${ }^{1}$ Hiperónimo que utiliza para designar 'eventos', 'estados', 'situaciones' ...

${ }^{2}$ Frente a la tradición española y en buena medida europea, utilizamos el término «conjunción» no para referirnos a una categoría gramatical o clase de palabra, sino para designar el tipo de relación semántica expresado por 'and', 'y'.
} 
disyuntivos sean generalmente palabras libres y no clíticos o afijos, que sean formas más largas que las de valor conjuntivo o que por lo común los mismos nexos sirvan para la unión de cláusulas y sintagmas, frente a la mayor tendencia a la diferenciación en el caso de la coordinación conjuntiva (Haspelmath 2004, 27).

Dentro de la disyunción, tradicionalmente se diferencian dos subtipos, establecidos por la lógica de tradición aristotélica y aplicados primeramente al latín: el inclusivo, si en una construcción coordinada [A o B] al menos uno de los dos miembros es verdad (ej. Para ese trabajo, tienes que hablar francés o alemán); y el exclusivo, si uno y solo uno de los dos coordinados es verdad (ej. Tienes que elegir francés o alemán). Esta dicotomía ha sido reformulada por varios investigadores, que frente a la definición propia de la lógica booleana según las condiciones de verdad que se establecen entre los elementos coordinados, optan por una interpretación de tipo modal o pragmático; no obstante, a pesar de replanteamientos como los de Haspelmath (2007), que habla de standard e interrogative disjunction respectivamente, o Mauri (2007; 2008; Mauri/van der Auwera 2012), que establece la oposición entre simple y choice-aimed alternative, en el fondo se sigue manteniendo un planteamiento dicotómico al que se le otorga condición de universal. ${ }^{3} \mathrm{Su}$ codificación lingüística es, sin embargo, diversa, con una gran variación no solo interlingüística, sino también intralingüística, de manera que no existe una correspondencia transparente y unívoca entre el tipo de relación semántica y el mecanismo lingüístico empleado (Ohori 2004).

Los estudios tipológicos establecen tres patrones fundamentales para la expresión [A o B] en lenguas que, como las europeas, presentan los mismos conectores con independencia de las categorías que unan (Mauri 2008, 163-170):

a) muchas poseen un único marcador válido para expresar inclusión y exclusión, como es el caso de todas las lenguas románicas salvo el rumano (español $o$, francés $o u$, italiano $o \ldots$ ), el inglés or o el alemán oder;

b) otras, además del marcador general, tienen otro específico para el significado 'exclusivo', como el vasco (edo es la disyunción general y ala la empleada para el valor exclusivo);

c) un tercer grupo presenta conectores diferentes para los dos tipos de disyunción, como el polaco (lub con valor inclusivo y czy exclusivo).

\footnotetext{
${ }^{3}$ Por nuestra parte, emplearemos los términos «inclusivo» y «exclusivo» por ser los usados de manera general en la bibliografía sobre las tres lenguas objeto de estudio en este trabajo, pero sin que ello signifique la asunción de los presupuestos de la lógica booleana.
} 
Hay que decir, no obstante, que esta clasificación tipológica de las lenguas necesariamente simplifica realidades particulares mucho más complejas, como tendremos ocasión de ver al ocuparnos de la disyunción en latín, en castellano medieval y en euskera. Sírvanos ahora de ejemplo el nexo discontinuo $o \ldots o$ del español actual, con conector antepuesto al primer miembro de la disyunción, construcción que a juicio de Jiménez Juliá (1986 y 1995; cf. también Camacho 1990 y 1999, Fornés 1994) sería la heredera de aut (cf. infra § 3) y serviría para expresar de forma inequívoca la exclusión: Tienes que elegir o francés o alemán. ${ }^{4}$ Pero aparte del hecho de que esta construcción de doble marcador está sujeta a algunas incompatibilidades sintácticas, ${ }^{5}$ Camacho llama la atención sobre ciertas limitaciones a la interpretación exclusiva derivadas del contexto sintáctico, así como Fukasawa (1985-1986) o Borrego Nieto (2000, 48ss.), quien muestra que con $o \ldots o$ no siempre se expresa que los miembros coordinados se excluyan entre sí, sino que se excluyen otras posibles opciones. De esta forma, con una frase como Para optar a ese puesto hay que tener o enchufe o experiencia, se quiere decir que cualquier cosa que no sea enchufe o experiencia es inútil para conseguir el puesto. Señala este autor que los nexos compuestos $(o \ldots o$, tanto ... como, ni ... ni) tienen como función cerrar la serie, «señalar que no hay en ella más miembros que los que se citan y excluir no a uno de los miembros, sino a cualquier otro que no haya sido mencionado» (Borrego Nieto 2000, 50). Es decir, la anteposición de la partícula a cada uno de los miembros implica en estos casos una enumeración exhaustiva y cerrada.

Por consiguiente, ni siquiera la construcción discontinua $o \ldots o$ codifica de manera unívoca el significado disyuntivo que quiere manifestar el hablante: el carácter real-factual o irreal-no factual de la cláusula, el contexto, el conocimiento del mundo y el universo compartido de los interlocutores son en muchos casos los que permiten discernir sobre la interpretación de la disyunción, que ofrece muchos más matices semánticos que el de la simple inclusión y exclusión. ${ }^{6}$ Así, en el ejemplo Tienes que elegir o francés o alemán, las tres marcas de «irrealidad» (perífrasis de obligación tener que, verbo elegir y correlación $o \ldots o$ ) no son suficientes para aclarar si la exclusión se refiere a los dos idiomas entre sí (el francés y el alemán se excluyen mutuamente), o si se están excluyendo otros posibles idiomas, siendo la elección entre el alemán y el francés

\footnotetext{
${ }^{4}$ No era así en castellano medieval, en el que la disyunción discontinua no expresaba necesariamente exclusión (Espinosa Elorza 1996, 277s.). Esta misma autora añade a $o$... o otros marcadores discontinuos, como quier ... quier/o.

5 Jiménez Juliá (1986) señala la imposibilidad de emplearlo con imperativos; Camacho (1990, 420ss. y 1999, $\S 41.3 .3 .1)$ se refiere a su agramaticalidad en las interrogativas y exclamativas. Lógicamente, los contextos de irrealidad no pueden evaluarse en términos de su valor de verdad, como ya señaló Dik (1968, 274-277).

${ }^{6}$ Recordemos a este respecto las implicaturas conversacionales de Grice (1989a y 1989b) que, desde una perspectiva pragmática, sirvieron para explicar los diferentes valores que adquieren los coordinadores en el contexto discursivo. Sobre las teorías de Grice y sus continuadores, cf. el detallado análisis de Haugh (2011).
} 
indiferente: Tienes que elegir o francés o alemán, como prefieras, pero no ruso. Solo si los dos interlocutores comparten la información sobre la lista completa de idiomas elegibles, la oración resultará inequívoca.

Es fácil comprobar, por tanto, que los valores semánticos de la disyunción no se limitan a la oposición inclusivo/ exclusivo, sino que comprenden un abanico amplio de significados. En realidad, ni siquiera la dicotomía entre conjunción y disyunción es tajante y formalmente unívoca, pues determinados contextos pueden inducir a la neutralización. Siguiendo con el ejemplo anterior, el empleo de un verbo que expresa capacidad hace a y y $o$ intercambiables: Puedes hablar en francés y/o en inglés.

Una visión renovada de los problemáticos límites entre semántica y pragmática en los conectores y de la combinación de significado codificado lingüísticamente e interpretación inferencial la ofrecen Mauri/van der Auwera (2011), que proponen una perspectiva dinámica que tiene en cuenta tanto sincronía como diacronía y en la que lo que es pragmático en una lengua o en alguno de sus estados diacrónicos, puede ser semántico en otra lengua o en otra etapa de la evolución de esa determinada lengua. Aun coincidiendo plenamente con este planteamiento, consideramos que un modelo semántico escalar permite explicar de manera más satisfactoria las relaciones entre ' $\mathrm{y}$ ' $\mathrm{y}$ ' $\mathrm{o}$ ' tanto en sincronía como en diacronía. Los dos elementos formarían parte de una misma escala de «inclusión-exclusión», con lo que en una lengua como el español actual tendríamos cuatro grados fundamentales:

$$
\underset{y \rightarrow o \text { (inclusivo }) \rightarrow o \text { (exclusivo) } \rightarrow y \text { no }}{\stackrel{\text { exclusión }}{\longrightarrow}}
$$

La gradualidad iría desde la conjunción positiva y [A y B] para expresar que los dos miembros se incluyen necesariamente, a la conjunción con el segundo miembro negado [A y no B], en la que este queda obligatoriamente excluido; en medio, los valores de inclusión o exclusión aparecen asociados a los tipos posibles de alternativa, que van desde la equivalencia entre los elementos o la indiferencia entre ellos, a otros más cercanos a y no, en los que la elección conlleva desechar las restantes posibilidades. ${ }^{7}$ La ambivalencia o, si se prefiere, neutralización de $n i$ en contextos de negación, que sirve para introducir los constituyentes tanto en construcciones conjuntivas como en

\footnotetext{
${ }^{7}$ Fundamentales resultan las relaciones entre negación, conjunción y disyunción, cuestiones que no podemos abordar en estas páginas. Para el caso del latín, cf. Orlandini (2001, §4).
} 
disyuntivas, la alternancia $y / o$ en contextos en los que la idea de selección es léxicamente explícita, como en «elegir entre $\mathrm{A} y / \mathrm{o} \mathrm{B} » . .$. , son hechos que apuntan claramente a la conveniencia de que $y$ y $o$ se analicen dentro de una misma escala. En nuestra opinión, esta progresión semántica es clave para entender las alternancias y usos considerados no prototípicos de los coordinadores, ya sea en latín, en español o en euskera, escalaridad que está en la base de los procesos diacrónicos que se van a describir.

\section{Conjunción y disyunción en latín}

\subsection{Vitalidad de los conectores}

Resulta sorprendente el alto número de coordinadores que existían en latín; los conjuntivos eran et, ac, atque, y el enclítico -que, y los disyuntivos, aut, uel, seu, siue, an y -ue. La yuxtaposición o coordinación asindética no era en absoluto desconocida en latín, pero se considera el mecanismo más rudimentario, propio del habla popular y familiar que reflejan determinadas obras teatrales o las cartas privadas (Bassols de Climent 1992, 318). ${ }^{8}$ En la lengua cuidada lo normal es la coordinación sindética, en la que es frecuente la alternancia de las partículas, manifestación a la vez de su vaguedad semántica y de la búsqueda de variatio por parte de los escritores. ${ }^{9}$

Como es bien sabido, este amplio inventario de nexos sufrió una drástica reducción al dar paso a las lenguas románicas, que casi sin excepción han conservado como únicas formas los resultados evolucionados de et y aut. Conocer la historia de su imposición en la geografía románica sobre el resto de conectores es una tarea pendiente para latinistas y romanistas, pero parece claro que el triunfo de et se explica por ser la forma funcionalmente general o no marcada (Coseriu 1977, 203 230), válida además para la unión de todo tipo de palabras y oraciones.

Su superioridad es constante en todas las épocas y en todos los tipos de textos, según se muestra en las siguientes tablas, que recogen los datos de la Library of Latin Texts Series A (LLT-A), los Monumenta Germaniae Historica (versión electrónica, eMGH) y el Corpus Documentale Latinum

\footnotetext{
${ }^{8}$ Como señala este mismo autor, también puede emplearse como recurso estilístico para acusar las contraposiciones, señalar la rápida sucesión de los hechos o dar a la narración un colorido arcaizante.

${ }^{9}$ La combinación de yuxtaposición y coordinadores, sin que se perciba una intención de distinguir los diversos agrupamientos, es señalada por Juret $(1933,156)$; asimismo, Fontaine $(1960,123)$ interpreta los casos de yuxtaposición en combinación o alternancia con la construcción sindética como una manifestación más de variación intencionada.
} 
Gallaeciae (CODOLGA): ${ }^{10}$

\begin{tabular}{|l|r|r|r|}
\hline LLT-A [n de frases que lo contienen] & \multicolumn{1}{|c|}{ et } & \multicolumn{1}{c|}{ atque } & \multicolumn{1}{c|}{ ac } \\
\hline Antiquitas (< ca. 200) & 98.319 & 17.238 & 14.111 \\
\hline Aetas Patrum I (ca. 200-500) & 334.103 & 24.527 & 19.066 \\
\hline $\begin{array}{l}\text { Corpus Pseudepigraphorum latinorum Ueteris Testamenti } \\
\text { (ca. saec. 4-7) }\end{array}$ & 443 & 28 & 18 \\
\hline Biblia sacra iuxta Uulgatam (ca. saec. 4-5) & 29.045 & 492 & 429 \\
\hline Aetas Patrum II (501-735) & 138.667 & 10.793 & 9.972 \\
\hline $\begin{array}{l}\text { Concilia oecumenica et generalia Ecclesiae catholicae } \\
\text { plerumque saec. 6-8) }\end{array}$ & 3.497 & 15 & 29 \\
\hline Medii aeui scriptores (736-1500) & 867.826 & 27.293 & 32.643 \\
\hline Recentior latinitas (1501-1965) & 57.141 & 5.753 & 10.998 \\
\hline TOTAL & $\mathbf{1 . 5 2 9 . 0 4 0}$ & $\mathbf{8 6 . 1 3 9}$ & $\mathbf{8 7 . 2 6 6}$ \\
\hline
\end{tabular}

\begin{tabular}{|l|r|r|r|}
\hline eMGH [n' de frases que lo contienen] & \multicolumn{1}{|c|}{ et } & \multicolumn{1}{c|}{ atque } & \multicolumn{1}{c|}{ ac } \\
\hline Aetas Patrum (ca. 200-735) & 36.455 & 3.855 & 3.588 \\
\hline Medii aeui scriptores (736-1500) & 271.595 & 20.078 & 25.778 \\
\hline Recentior latinitas (1501-1965) & 297 & 5 & 38 \\
\hline TOTAL & $\mathbf{3 0 8 . 3 4 7}$ & $\mathbf{2 3 . 9 3 8}$ & $\mathbf{2 9 . 4 0 4}$ \\
\hline
\end{tabular}

\begin{tabular}{|l|r|r|r|}
\hline eMGH [n' de ocurrencias] & \multicolumn{1}{c|}{ et } & \multicolumn{1}{c|}{ atque } & \multicolumn{1}{c|}{ ac } \\
\hline Aetas Patrum (ca. 200-735) & 56.134 & 4.062 & 3.882 \\
\hline Medii aeui scriptores (736-1500) & 547.296 & 22.140 & 30.144 \\
\hline Recentior latinitas (1501-1965) & 516 & 5 & 40 \\
\hline TOTAL & $\mathbf{6 0 3 . 9 4 6}$ & $\mathbf{2 6 . 2 0 7}$ & $\mathbf{3 4 . 0 6 6}$ \\
\hline
\end{tabular}

\begin{tabular}{|l|r|r|r|}
\hline CODOLGA & \multicolumn{1}{c|}{ et } & \multicolumn{1}{c|}{ atque } & \multicolumn{1}{c|}{ ac } \\
\hline$\left[\mathbf{n}^{\mathbf{0}}\right.$ de ocurrencias] & $\mathbf{1 7 7 . 8 4 6}$ & $\mathbf{3 . 9 3 2}$ & $\mathbf{2 . 6 1 4}$ \\
{$\left[\mathrm{en}\left(\mathrm{n}^{\circ}\right.\right.$ de documentos)] } & $(8.467)$ & $(2.309)$ & $(1.452)$ \\
\hline
\end{tabular}

${ }^{10} A c$ es en realidad una variante de atque, empleada la primera únicamente ante consonante. No hemos incluido la enclítica -que por la imposibilidad de buscarla de manera automática en los corpus utilizados, pero según los estudiosos, su empleo cayó en desuso en la lengua hablada a comienzos de la época imperial (Löfstedt 1911 y 1920, 96ss.; Juret 1933, 154; Bassols de Climent 1992, 320s.; etc.), si bien en el periodo clásico y tardío es bastante frecuente en los textos literarios, aunque siempre muy por detrás de $e t$. 
A pesar de su constancia, se aprecia que la Edad Media constituye el periodo de mayor empleo de et respecto a atque, ac, lo que contrasta fuertemente con el caso de aut. Una mirada superficial a los datos cuantitativos nos enfrenta a un problema de naturaleza empírica: solo en el periodo arcaico (y después, de manera aislada, en los textos de la Vulgata), aut es mayoritario, mientras que en las restantes épocas el preferido es $u e l$, que alcanza su momento álgido precisamente en la Plena Edad Media; de hecho, en los documentos de escritura latina coetáneos o inmediatamente anteriores al desarrollo de una escritura romance consistente, ${ }^{11}$ uel es el conector disyuntivo por excelencia, a gran distancia de aut y de las otras partículas, que, sin embargo, mantienen en la escritura una vitalidad nada desdeñable:

\begin{tabular}{|l|r|r|r|r|}
\hline LLT-A A [n de frases que lo contienen] & \multicolumn{1}{c|}{ uel } & \multicolumn{1}{c|}{ aut } & \multicolumn{1}{c|}{ siue } & seu \\
\hline Antiquitas (< ca. 200) & 6.097 & 14.925 & 1.479 & 708 \\
\hline Aetas Patrum I (ca. 200-500) & 27.935 & 22.333 & 8.124 & 858 \\
\hline $\begin{array}{l}\text { Corpus Pseudepigraphorum latinorum Ueteris } \\
\text { Testamenti (ca. saec. 4-7) }\end{array}$ & 97 & 72 & 22 & 6 \\
\hline Biblia sacra iuxta Uulgatam (ca. saec. 4-5) & 203 & 439 & 120 & 1 \\
\hline Aetas Patrum II (501-735) & 14.465 & 7.885 & 4.339 & 645 \\
\hline $\begin{array}{l}\text { Concilia oecumenica et generalia Ecclesiae } \\
\text { catholicae (plerumque saec. 6-8) }\end{array}$ & 108.423 & 38.419 & 22.442 & 7.786 \\
\hline Medii aeui scriptores (736-1500) & 5.058 & 3.529 & 2.199 & 922 \\
\hline Recentior latinitas (1501-1965) & $\mathbf{1 6 2 . 3 0 1}$ & $\mathbf{8 7 . 6 9 7}$ & $\mathbf{3 8 . 7 2 8}$ & $\mathbf{1 0 . 9 2 6}$ \\
\hline TOTAL & & 95 & 0 \\
\hline
\end{tabular}

\begin{tabular}{|l|r|r|r|r|}
\hline eMGH [n' de frases que lo contienen] & \multicolumn{1}{c|}{ uel } & \multicolumn{1}{c|}{ aut } & \multicolumn{1}{c|}{ siue } & seu \\
\hline Aetas Patrum (ca. 200-735) & 3.823 & 2.590 & 365 & 423 \\
\hline Medii aeui scriptores (736-1500) & 28.732 & 14.417 & 5.658 & 5.799 \\
\hline Recentior latinitas (1501-1965) & 4 & 2 & 2 & 3 \\
\hline TOTAL & $\mathbf{3 2 . 5 5 9}$ & $\mathbf{1 7 . 0 0 9}$ & $\mathbf{6 . 0 2 5}$ & $\mathbf{6 . 2 2 5}$ \\
\hline
\end{tabular}

\begin{tabular}{|l|r|r|r|r|}
\hline eMGH [n' de ocurrencias] & \multicolumn{1}{c|}{ uel } & \multicolumn{1}{c|}{ aut } & \multicolumn{1}{c|}{ siue } & seu \\
\hline Aetas Patrum (ca. 200-735) & 4.821 & 3.880 & 495 & 540 \\
\hline Medii aeui scriptores (736-1500) & 41.090 & 22.154 & 7.874 & 6.873 \\
\hline
\end{tabular}

\footnotetext{
11 Aunque hablamos aquí y en adelante de documentos plenomedievales de «escritura latina», quizá fuera más exacto decir «aparentemente no romance», pues los usos gráficos y morfológicos latinos en muchos casos no llegan a ocultar una sintaxis plenamente vernácula.
} 


\begin{tabular}{|l|r|r|r|r|}
\hline Recentior latinitas (1501-1965) & 5 & 7 & 2 & 3 \\
\hline TOTAL & $\mathbf{4 5 . 9 1 6}$ & $\mathbf{2 6 . 0 4 1}$ & $\mathbf{8 . 3 7 1}$ & $\mathbf{7 . 4 1 6}$ \\
\hline
\end{tabular}

Más sorprendente si cabe es que en el CODOLGA aut no es muy superior a siue y seu, y entre las tres no alcanzan el $65 \%$ de las ocurrencias de $u e l$ :

\begin{tabular}{|c|c|c|c|c|}
\hline CODOLGA & uel & aut & siue & seu \\
\hline [no de ocurrencias] & 19.562 & 2.926 & 2.327 & 2.072 \\
\hline [en (n ${ }^{\circ}$ de documentos)] & $(5.670)$ & $(1.673)$ & $(1.376)$ & $(1.140)$ \\
\hline
\end{tabular}

Estos usos peninsulares no son, desde luego, exclusivos del área gallega; en Castilla es habitual que los documentos notariales de los siglos XI y XII alternen en un mismo contexto las partículas disyuntivas, lo que solo puede interpretarse como deseo de variatio en los estrictos límites del latín escrito. Basten un par de ejemplos. La famosa carta de arras del Cid Campeador por el casamiento con doña Jimena, del año 1074, presenta la siguiente sucesión de conectores:

Si quis tamen ab hodierno die tam ex me quam de propinquis aud filiis vel nepotis seu de extraneis adque heredibus meis (Garrido Garrido 1983, 63).

En el mismo fondo de la Catedral de Burgos, en un privilegio del rey Sancho II del año 1068 aunque conservado en una copia del siglo XII, leemos:

Aditio autem ut prefate uille seu monasteria uel ecclesias siue diuisas que suprascripte sunt uel que uos aut successores uestris aquirere potueris non habeant castellariam aut annubda uel fossatera ... (Garrido Garido 1983, 56).

Hay que decir que estas manifestaciones de variatio en el latín notarial se dan principalmente en las enumeraciones, pero en cualquier caso, si en los documentos de la Plena Edad Media, cuando el latín solo era una variedad escrita y en las lenguas romances solo se empleaban los resultados evolucionados de aut, encontramos todas las partículas en alternancia y con claro predominio de uel, hay que suponer, como hacen la mayoría de los gramáticos, que la realidad del latín oral había sido otra, y que aut había sido la forma preferida en la lengua hablada y popular. Los textos nos esconden la historia real de estos elementos, de su extensión y distribución sociolingüística, de su vitalidad en la lengua oral y de las fechas en las que aut se impuso definitivamente; lo único que podemos deducir es que el latín escrito de los siglos centrales de la Edad Media era en este punto muy distinto del romance hablado coetáneo. 


\section{$3.2 \mathrm{uel} /$ aut}

En cuanto al valor en el latín clásico de los dos coordinadores disyuntivos más frecuentes, uel y aut, únicos que realmente han recibido la atención de los investigadores, es general la caracterización de uel como inclusivo, frente al carácter exclusivo de aut, dicotomía que, como decíamos antes, ha sido la base para la descripción de la disyunción en las lenguas modernas. Un análisis detenido del reparto de estos dos conectores en los textos muestra, sin embargo, que la oposición bipolar no se cumple ni permite explicar determinados matices, lo que lleva a Orlandini (2001) a establecer dos empleos débiles o inclusivos (compatibles con la idea copulativa) y dos fuertes: los primeros corresponden al uso de $u e l$ en contextos no factuales positivos y de aut en contextos no factuales negativos; los fuertes corresponden a dos funciones de aut, como disyunción exclusiva y como equivalente a la conjunción copulativa et non, lo que pone nuevamente de manifiesto la cercanía semántica de uel a 'y' y de aut a 'y no'.

Que uel proceda de uelle, imperativo de uolo (Riemann 1886), ${ }^{12}$ explica que sirviera para expresar indiferencia ante la elección entre los miembros coordinados, acercándose de ese modo al significado conjuntivo, hasta el punto de que con frecuencia equivale a $e t,{ }^{13}$ valor especialmente frecuente en el latín visigodo de escritores como San Isidoro de Sevilla o San Braulio (Riesco 1971; Andrés Sanz 2006, 111). Pero al lado de este uso también se emplea uel como disyunción exclusiva: Allies (2008) trae ejemplos tomados de textos clásicos, si bien señala que no son habituales; por su parte, Bassols de Climent $(1992,332)$ dice que este empleo de uel es solo frecuente en textos historiográficos, y para Tovar (1946, 175s.), es uso propio del latín tardío y se debe a confusión hipercorrecta. Según los datos que maneja Allies (2008), durante los siglos IV y V en la península ibérica es raro encontrar uel como disyuntiva exclusiva, mientras que es muy frecuente como nexo conjuntivo; a partir del siglo VII, sin embargo, uel recupera su posición como disyunción exclusiva sin perder su uso conjuntivo, lo que este autor interpreta como prueba de que ya no se empleaba en la lengua hablada, sino que «It now existed as a grammatically empty particle,

${ }^{12}$ El mismo desgaste semántico del verbo querer se produce en el conector discontinuo medieval quier ... quier, que para Espinosa Elorza $(1996,273)$ podría ser el heredero de uel. Ocurre lo mismo con sea ... sea, ya documentado en latín (sit ... sit).

${ }^{13}$ Lo señala Du Cange, así como los gramáticos desde finales del siglo XIX o comienzos del XX: Riemann (1886, 569), Bonnet (1890, 315), Stolz/Schmalz (1910, 502), Löfstedt (1911, 198), Svennung (1935, 495s.) y otros muchos tras ellos. 
unconstrained by the rules of the spoken language» (83).

Por otra parte, aut se utilizó, ya en latín clásico, con los valores considerados propios de uel, sirviendo para agrupar tanto términos que se excluyen como mutuamente inclusivos (Juret 1933, 158; Jennings 1994, 239-251, Jennings/ Hartline 2009, entre otros). Pero aut también se emplea en lugar de et, sola, en correlación (aut ... aut $=$ et ...et) o en combinación con la conjunción (aut ... et) (TLL, s. v. aut; Stolz/Schmalz 1928, 247e, Niermeyer 1976, s. v.), ${ }^{14}$ hechos todos que nos ponen una vez más ante la evidencia de los borrosos límites entre conjunción y disyunción y que invitan a concebir estas relaciones semánticas dentro de una misma escala, según proponíamos.

Creemos que este planteamiento ayuda a entender por qué en el paso del latín a las lenguas románicas se perdió la partícula $u e l$, a pesar de su predominio en los textos latinos de toda época. Parece razonable pensar que su situación intermedia en la escala de inclusión-exclusión y su consiguiente indefinición semántica debilitaran su posición como coordinador tanto conjuntivo como disyuntivo, inutilizándola para su conversión en el nexo disyuntivo general y precipitando su pérdida (Jiménez Juliá 1986, 164s.; Allies 2008, 80-83). Además, en la gama de relaciones disyuntivas de significación no exclusiva, uel competía con seu y siue, lo que tuvo que ser un factor más de debilitamiento. Por su parte, aut fue siempre la partícula disyuntiva semánticamente más fuerte, lo que propició que en la reducción del inventario de nexos coordinantes que se produjo en las lenguas románicas triunfaran las formas prototípicas de los dos extremos de la escala: la conjuntiva et y la disyuntiva aut.

\subsection{Reforzamiento de los conectores}

La variedad de coordinadores del latín y su laxitud significativa favorecieron su progresivo desgaste, lo que se manifestó en el desarrollo de diversos mecanismos de refuerzo, uno de los cuales fue la anteposición del nexo a cada miembro de la coordinación, de manera que el primero también fuera precedido por él (Juret 1933, 156-159; Ernout 1964, 376; etc.): et ... et, et ... -que, -que ... -que, etc., aut ... aut, uel ... uel, aut ... -ue, etc., repetición a la que se le atribuye generalmente un valor de mayor expresividad o énfasis y que es abundante desde el latín arcaico. ${ }^{15}$

\footnotetext{
${ }^{14}$ Lo contrario, et $=$ aut, es más raro. Correspondencias del tipo seu ... uel ... et, uel ... uel ... et, uel ... -ue ... aut, etc. son recogidas por Stolz/Schmalz (1910, § 260).

15 Jiménez Juliá (1986) niega que $o \ldots o$ en español tenga mero valor estilístico y considera a la construcción heredera del significado disyuntivo exclusivo prototípico de aut. Cf. lo comentado en $\S 2$.
} 
Otra manifestación más del debilitamiento semántico de los nexos y su necesidad de reforzamiento es su empleo pleonástico, muy especialmente de los conjuntivos -que y et. Las formaciones, muchas de ellas gramaticalizadas, con -que enclítico (quique, absque, ideoque, itemque, iamque, itaque, uterque, quisque, la misma atque ...), así como et ideo, et item, et iam, et ita ..., son muy antiguas, y se ha dicho que expresaban un mayor énfasis que las formas simples correspondientes (Sabbadini 1918).

La tendencia al uso de et como refuerzo de otras partículas, que realmente se explica por el desgaste de ambos componentes (Schrijnen/Mohrmann 1937, 71), es un rasgo que va en aumento y que se considera característico del latín tardío y vulgar (Löfstedt 1911, 95; Sabbadini 1918; Bastardas Parera 1953, 179s.; Riesco 1971, 189-194). Se halla profusamente en los textos latinos de la Plena Edad Media: et etiam = etiam, et quoque = quoque, también postpuesta: ergo et, etiam et, nam et, sed et... o nec non et, construcción esta última que será la más frecuente en la documentación latina de la cancillería castellana en la segunda mitad del XII y primera década del XIII (Pérez González 1985, 175). No menos común en latín tardío es el empleo aparentemente expletivo de et al inicio de frase u oración.

\section{Castellano medieval do}

La labilidad de las fronteras entre $y$ у $o$ fue igualmente acusada en castellano medieval, ${ }^{16}$ lo que se manifiesta en la alternancia de los dos nexos para expresar la idea conjuntiva-disyuntiva. El fenómeno ha sido atendido por Saralegui/Pérez-Salazar (1992, § 3) al estudiar la coordinación de sinónimos en textos jurídicos (ej. permuta o cambio, cambio y permuta), neutralización de significado entre los dos conectores que atribuyen precisamente a la sinonimia de los coordinados. ${ }^{17}$ No obstante, la alternancia no es exclusiva de los binomios sinonímicos, sino que también es frecuente en las enumeraciones:

Si Cauallo o yegua fuere por un dia en pennos aya en engueras. Seys dineros. \& si denoche un sueldo. \& el mulo o el Asno. por el dia tres dineros. \& enla noche Seys dineros. Et si el Cauallo muriere yaziendo en pennos. peche ciento suel $\mid{ }^{15} \mathrm{dos}$. \& por la yegua Cinquaenta sueldos. \& por mulo o por el Asno; veynte

\footnotetext{
${ }^{16}$ Por ejemplo, Hanssen $(1966, \S 681)$ dice que «En castellano antiguo, $o$ a menudo es conjunción copulativa», uso que -señala- ya se daba en la latinidad tardía.

17 En realidad, la pareja sinonímica es una práctica estilística conocida ya en latín clásico pero desarrollada especialmente en la latinidad tardía y en el nacimiento de las lenguas romances (Politzer 1961, 484), y mantenida mucho tiempo después.
} 
sueldos. [...] Si cauallo. o yegua. Mulo \& Asno \& buey $\mid{ }^{16}$ compraren enla carrera del Rey con dos testigos o con tres non den otor (CODCAR0156, Alfonso X, Arlanzón, 1256).

\& por los sseruiçios $\mid{ }^{5}$ que me ffaredes de aqui adelante. Perdono uos \& quito uos las demandas que yo auja o podria auer contra los cogedores \& ssobre cogedores o rrecabdadores $\left.\right|^{6} \mathbf{0}$ arrendadores delos sseruiçios \& delos otros pechos que por el Rey mio padre que dios perdone o por mj cogiestes o rrecabdastes o Arrendastes en la villa $\left.\right|^{7}$ de Burgos \& en ssu alffoz \& en todas las otras meryndades de Castiella. pechos \& martinjegas o derechos o los diezmos delos Puertos dela mar ${ }^{8}$ o dela tierra. o las mjs monedas que yo mande labrar o la mj chançelleria o la ssissa... (CODCAR0717, Fernando IV, Burgos, 1304).

Los ejemplos anteriores sirven asimismo para ilustrar el característico polisíndeton de los textos medievales y la apertura de frase con ' $y$ ', fenómenos que continúan y desarrollan usos latinos y que, como decíamos, evidencian la debilidad semántica del nexo conjuntivo.

En lo que sí se diferencia el español del latín - en sintonía con las demás lenguas románicas - es en la reducción del inventario de conectores, de los que, para la significación disyuntiva, solo sobrevive la forma evolucionada de aut, $o$, y su variante fonética $u$. Los posibles derivados de $u e l$, seu, siue ... no solo desaparecen de la lengua hablada, sino también de la escrita, al contrario de lo que hemos visto para el latín de la Plena Edad Media. En efecto, los primeros documentos que hacen uso de una escritura romance consistente, a finales del siglo XII y, sobre todo, desde los años veinte del siglo XIII, utilizan exclusivamente la forma $o$, y empiezan a incorporar algunas estructuras discontinuas como quier ... quier, sea ... sea, que podían alternar uno de los marcadores con el general $o$ : quier ...o, sea ... o (Espinosa Elorza 1996).

Por eso es importante el hallazgo de un nuevo coordinador disyuntivo que, además, no forma parte de una construcción discontinua: $d o$. Por el momento lo hemos encontrado únicamente en dos documentos del siglo XIII procedentes del mismo monasterio del norte de la provincia de Burgos, San Salvador de Oña. Se emplea tres veces en el primer documento, de 1237 (CORHEN0116): ${ }^{18}$

el qui ouiere jugu de bues o de bestias ajude con ell. \& el qui ouiere un bue do bestia ajude con ell. \& el quj $\mid 5$ non ouiere bue. o bestja. ajude nos con so cuerpo [...] A tal pleytu uos fazemos esta $\mid 7$ mercet. \& est lessamiento de las sernas. ke qual sequier de uos. o de los ke seran. ke ouiere iugu de bues. o de bestias. o si ouiere heredat pora ell. ke nos de kada un anno. dos almudes $\left.\right|^{8}$ de pan. ell unu de trigo. \& ell otro de ordio. \& un sueldo de dineros. si fueren los bues do las bestias tales con ke pueda omne labrar. El qui ouiere un bue. do bestia con ke pueda $\mid{ }^{9}$ labrar. o heredat pora un bue. denos kada un anno. un almud e medio de pan.

Para que no haya dudas sobre la corrección de la lectura, ofrecemos su reproducción facsimilar:

1.4

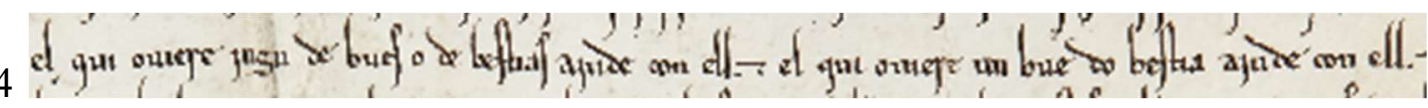

${ }^{18}$ Archivo Histórico Nacional, Clero Secular_Regular, car. 285, n. 6. 


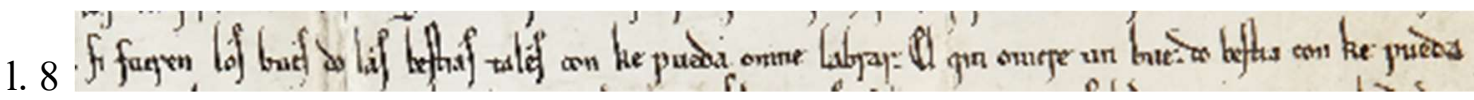

En el segundo diploma, de 1247 (CORHEN0137),${ }^{19}$ do se utiliza en una sola ocasión:

Et si ferrant yuannes an ${ }^{17}$ te finare dest plazo finqe la meatad en sos fijos. si fueren nuestros uassallos. \& ellos otro si sean tenudos de dar la renda. \& si ferrando ${ }^{18}$ finare finqe en ferrant yuannes do en sos fijos. \& den ellos la renda.

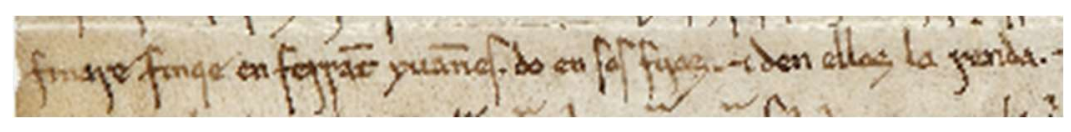

De cuatro casos, todos con significado inclusivo, difícilmente podríamos sacar conclusiones sobre su valor o distribución respecto a $o$, nexo con el que alterna en idéntico contexto, como se ve en el primer fragmento transcrito. Ni siquiera se pueden aducir razones fonéticas para explicar la presencia de $d o$, que se da dos veces tras -e (bue do bestia), pero también tras -s, por lo que solo el deseo de variatio entre $o$ y do parece justificar la alternancia.

A la espera de encontrar más documentaciones que quizá permitan establecer condicionamientos morfosintácticos, semánticos o pragmáticos, la pregunta inmediata es de dónde procede esta forma. Nuestra propuesta es el pleonasmo latino et aut.

\section{Pleonasmo latino et aut}

Todo lo expuesto en el apartado 3, especialmente en 3.3 (la equivalencia semántica entre conjunción y disyunción, la repetición estilística del nexo delante de cada miembro coordinado, la apertura de oración con et y la abundancia de construcciones pleonásticas con et) justificaría desde el punto de vista teórico la existencia del pleonasmo et aut $=$ aut, que de aplicarse en él la evolución fonética que dio lugar al castellano, sería un perfecto étimo de (e)do, como veremos más adelante.

No obstante, lo cierto es que et aut no aparece recogido en ninguna gramática latina ni estudio, ${ }^{20}$ de manera que los autores que dan cuenta de combinaciones pleonásticas en sus trabajos no

\footnotetext{
${ }^{19}$ Archivo Histórico Nacional, Clero Secular_Regular, car. 286, n. 2.

${ }^{20} \mathrm{Al}$ menos en los trabajos citados a lo largo del artículo y recogidos en la bibliografía final, lo que nos evita el tener que enumerarlos aquí.
} 
contemplan et aut. Los fundamentos teóricos son sólidos, pero faltaría la base documental. ¿O no?, porque de la misma manera que aut fue la forma que triunfó en todas las lenguas románicas, a pesar de ser siempre minoritaria respecto a uel en los textos, quizá et aut fuera una combinación propia de la lengua hablada a la que apenas se diera cabida en los escritos.

En este sentido, el TLL (VII, s. v. et) sí trae et uel, que por ejemplo aparece en un documento del Monasterio de San Salvador de Oña del año 993: «duplicatu et bel melioratu» (CORHEN0005). Y es que los pleonasmos son muy frecuentes en la documentación notarial latina de la Castilla de los siglos X-XI, la mayoría formados por dos elementos de significación aditiva, del tipo et etiam, atque et, et-que ..., algunos tan llamativos como «tam mouile quam etiam et inmobilem» en un documento del año 978 de la Catedral de Burgos (Garrido Garrido 1983, 20).

\section{1 et aut ... aut}

Lo que sí se documenta con profusión en el latín de todas las épocas es la estructura et aut ... aut, es decir, con el aut (o uel) precediendo al primer miembro de la disyunción. Veamos unos pocos ejemplos, la mayoría, como podrá apreciarse, con aut inclusivo:

atque ipsum illud peccatum erit extenuandum, ut quam minimum obfuisse videatur, et ant turpe aut inutile demonstrandum tali de homine supplicium sumere (LLT-A, M. Tullius Cicero, De inuentione).

ac poetae quidem nectar ambrosiam epulas conparant et aut Iuventatem aut Ganymedem pocula ministrantem, tu autem Epicure quid facies? (LLT-A, M. Tullius Cicero, De natura deorum).

Vehementius idem facit, etiam adurendo, auripigmentum cum chalcitide, et aut nitro, aut calce, aut charta combusta: item sal cum aceto; vel ea compositio, quae habet chalcitidis, capitulorum punici mali, aloes, singulorum p. (LLT-A, A. Cornelius Celsus, De medicina).

Ubi ista se remiserunt, jam que is locus prurit, et aut sublividus, aut subalbidus est, matura suppuratio est: ea que, ubi vel per ipsa medicamenta, vel etiam ferro aperta est, pus debet emitti (LLT-A, A. Cornelius Celsus, De medicina).

Callus autem neminem fallit, quia durus est, et aut albus, aut pallidus (LLT-A, A. Cornelius Celsus, De medicina).

Un pleonasmo formado por dos conectores disyuntivos, dentro de esta misma correlación et aut ... aut, lo hallamos en este otro caso:

siue ergo nodum quaestionis huius explicare possimus, siue conatus noster difficultati eius fortasse subcumbat, et aut uel cogitare digne non possim quod dicam, aut forte dicere quod potuero cogitare, feruete in operibus misericordiae (eMGH, Augustinus Hipponensis, Sermones). 


\section{2 et aut}

Pero a pesar de no haber sido recogido por los estudiosos, sí es posible encontrar casos de et aut inequívocamente pleonástico. No son muchos los ejemplos, pero al menos podemos mostrar los siguientes:

qui autem alteram Galliam et aut Syriam aut Macedoniam, tamen alterum retinet, in utriusque pari scelere disparem condicionem facit (LLT-A, M. Tullius Cicero, De prouinciis consularibus oratio).

nam ut signa quae non habent caput [et] aut aliquam aliam partem, nihil[h]o minus in reliquis membris eorum esse possunt analogiae, sic in uocabulis casuum possunt item fieri ac reponi quod aberit (LLT-A, M. Terentius Uarro, De lingua latina $)^{21}$

Ipse autem Rubiacensem cenobium, quod hinc indeque montibus septus, ab oriente panditur aditum et aut procul eminet urbi, visendi gratia consulendique adire properabat (eMGH, Vita Boniti ep. Arverni, s. VIII).

Robertus: Pars civium fuge subsidio liberatur, pars vero maxima gladiis ceditur et aut vinculis mancipatur (eMGH, Albericus monachus, Trium-fontium, Chronica a monacho Novi-monasterii Hoiensis interpolata, 1241).

Et si aliquis ominis et aut ex gentibus meis qui tiui disturbatione fecerit / nec inmodice aut in iudicio miseri, quomodo det ipso solare cum tale foro in duplo uel triplo (Ruiz Asencio, Colección documental del Archivo de la Catedral de León (775-1230), IV, doc. 1192, de 1073?).

Si quis vero aliquis de infanzonibus aut de potestatibus voluerit extrahere de monasterio illo aliquas facultates, aut hereditates, ducat regem ad Sanctum Iohannem, et ante regem, et abatem de illo monasterio, et aut omnes Seniores de illa claustra, iuret per propria manu sua super illo altare (CORDE, Carta judicial relativa a San Juan de la Peña, 1062).

En alguno, como este último, la secuencia parece tener más bien valor conjuntivo que disyuntivo, algo que tampoco ha de sorprender, según la gradación y a veces equivalencia semántica entre nexos conjuntivos y disyuntivos que venimos señalando.

El único caso de sucesión de coordinadores que hemos hallado en el CODOLGA ${ }^{22}$ es un aut et, pleonasmo que el editor corrige, proponiendo la supresión de et:

do uobis, rogo ut primum dicatis fratri meo Iohanni Adefonsi, aut [et] sobrinis meis filiis Arias Martini; et si ipsi uoluerint (CODOLGA, Domínguez Casal, El Monasterio de Santa María de Meira y su colección diplomática, doc. de Meira de 1182).

Observamos que en varias ocasiones los editores intervienen en la secuencia marcando entre corchetes el elemento que les parece superfluo o incorrecto, ${ }^{23}$ lo que obliga a pensar que

\footnotetext{
${ }^{21}$ El corchete encierra el texto que el editor considera superfluo o incorrecto.

${ }^{22}$ Búsqueda realizada en el arco cronológico de los años 1070-1225.

${ }^{23}$ Los criterios de edición no lo especifican, pero suponemos que en el caso siguiente la marcación entre ángulos no
}

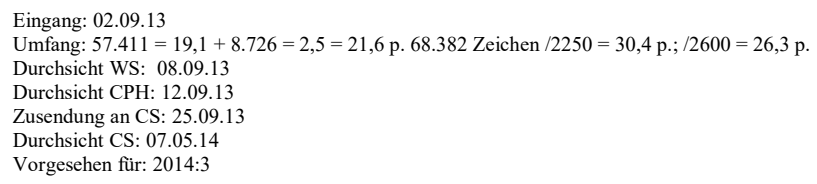


probablemente algunos de estos pleonasmos hayan sido «corregidos» y eliminados de las ediciones en un deseo de ofrecer textos depurados y normalizados, intervención de los editores de la que ya se quejaba Sabbadini en 1918, dando ejemplos concretos. En todo caso, a pesar de la escasez documental, no podemos perder de vista la fractura de la correspondencia entre escritura y oralidad que explica el desequilibrio de uel y aut (cf. supra 3.1); además, ya hemos visto que los gramáticos sí se hacen eco de et uel. Por otro lado, no descartamos que la frecuencia de et aut como introductor del primer elemento en la correlación et aut ... aut favoreciera su reinterpretación como nexo compuesto y su empleo con este valor en la lengua hablada.

\section{Evolución et aut $>(e) d o$}

Demostrada la existencia de et aut, la evolución castellana esperable sería edo, con sonorización de la consonante sorda intervocálica y monoptongación del diptongo latino au, forma que por el momento no hemos documentado; posteriormente, el resultado *edo dio lugar a do, evolución fonética que no presenta dificultades. La aféresis o pérdida de la vocal inicial en castellano es sobradamente conocida: afecta a todo el paradigma de los pronombres átonos de tercera persona, procedentes del demostrativo latino ( $l o<$ ILLUM-ILLUD, $l a<$ ILLAM, $l e<$ dativo ILLI), demostrativo que también es el étimo del artículo determinado el, la, lo, que solo en el caso del masculino presenta la forma con apócope en lugar de con aféresis. No obstante el triunfo del artículo el, en el castellano medieval de finales del siglo XII y primeras décadas del XIII encontramos la variante masculina elo, lo, de especial arraigo en el norte de Castilla, donde también hallamos hasta mediados del XIII las asimilaciones enna $<$ en la, enno $<$ en lo, que exigen la aféresis previa en el artículo. $^{24}$ La pérdida de la vocal inicial también se produce en palabras léxicas, como bispo 'obispo' < EPISCOPU, ${ }^{25}$ Mérida $<$ EMERita (Augusta), Millán < AEMiLianu, y de manera habitual

indica texto considerado superfluo, sino corrección del editor: «Et si aliqus ommo te ad iudicio pedierit, pro ipsas terras et <aut> pro / ipsas cerasales qui in ista karta resona, que ego Uela, aut uxore sue, / aut filiis, non uoluerimus auctoricare uel uindicare ad partes que uestras» (Fernández Flórez/Herrero de la Fuente, 1999, doc. 53, de 1001).

${ }^{24}$ Es precisamente la secuencia de preposición + artículo el origen, según Menéndez Pidal (1972, § 62.3), de la aféresis. Quizá el ejemplo más temprano es el que aporta el propio Menéndez Pidal, «jn los pumares» 'en los manzanares', de un documento de leonés del siglo X. Es sin duda en León donde las amalgamas del tipo enno se dieron primero y durante más tiempo, pero, como hemos dicho, no son ajenas al castellano. En cuanto a la forma del femenino el $(<$ illam $)$, apocopada ante palabra que empieza por vocal, tuvo una gran vitalidad durante siglos, y todavía en el XVII se encuentra esporádicamente ante $e$ - (el espada), para quedar finalmente limitada a su anteposición a /á-/ tónica.

${ }^{25}$ Según Corominas/Pascual (1980-1991, s. v.), la $o$ de la forma triunfante obispo se debería al reanálisis de elo bispo > el obispo. 
en el navarroaragonés medieval, con formas como glesia 'iglesia' < ECCLESIA, que precisamente también hallamos en un documento burgalés de 978: «Hanc sic concedimus et offerimus glesie uestre» (Garrido Garrido 1983, 19).

Para el paso de edo a $d o$, las razones pueden ser varias y complementarias. Por un lado, la reducción de coordinadores a los dos triunfantes $y-o$ apunta claramente a la búsqueda de una correspondencia biunívoca entre conectores y los dos polos semánticos conjuntivo - disyuntivo; al menos hasta mediados del siglo XIII, los textos presentan como variante mayoritaria, si no exclusiva, $e$, si bien lo absolutamente general es el empleo del signo tironiano, lo que hace imposible conocer la realidad fónica de su pronunciación. Más allá de la etimología, de la que los hablantes no serían conscientes, la sílaba inicial $e$ - podía asociarse al coordinador conjuntivo, mientras que la sílaba - do era fonéticamente más cercana al conector disyuntivo general $o \mathrm{y}$, en consecuencia, más fácil de relacionar semánticamente con este. Este hecho, sumado a la atonicidad del nexo y a la probable atracción hacia el monosilabismo ejercida por los otros nexos coordinantes, pudieron favorecer la aféresis de $e$-, por lo que nada extraña que a mediados del siglo XIII el coordinador fuera ya do y no edo.

\section{Vasco edo}

Queda por explicar la relación, más que evidente, entre el castellano do y el vasco edo. En el apartado 2 decíamos, citando a Mauri (2008), que el vasco pertenecía al grupo de lenguas que además de un marcador disyuntivo general, tienen otro específico para el significado exclusivo. La mayoría de los gramáticos desde finales del siglo XIX y comienzos del XX establecen la señalada oposición entre edo inclusivo y ala exclusivo, si bien ya Villasante (1979) y después Michelena (1992, s. v. edo) señalaron el carácter general de edo, que se usa «tanto para relacionar dos o más posibilidades que se excluyen, como para expresar la indiferencia o intercambiabilidad de los términos» (ib.). ${ }^{26} \mathrm{Al}$ igual que en latín y en español, edo (y ala) puede preceder a cada miembro de la disyunción, edo ... edo, solo o con el elemento dela: edo dela ... edo dela 'sea ... sea ...' (edo dela 'o sea, es decir'), aunque también existen las combinaciones edo dela ... edo, edo ... edo dela.

\footnotetext{
${ }^{26}$ Una descripción completa de los usos y funciones de estas partículas puede verse en Euskaltzaindia (1994) y en trabajos recientes, como Hualde/Ortiz de Urbina (2003, § 4.11.1), donde se analizan los valores que poseen dependiendo del tipo de constituyentes que unan y de la modalidad oracional, destacando tanto las diferencias como los usos que comparten.
} 
No faltan tampoco las formaciones pleonásticas, entre las que hay que destacar edota, literalmente 'o y', que es el tercer coordinador disyuntivo más frecuente en vasco.

Como variantes formales de edo se documentan ero y eo, y según las encuestas dialectales realizadas por el equipo de Rosa Mirem Pagola en Vizcaya, también se recoge $d o,{ }^{27}$ si bien en los escritos antiguos no se registra. La aféresis en edo no es, por tanto, equiparable a la que ocurre en el coordinador conjuntivo eta - ta - da, esta última solo en textos occidentales, según afirmación de Michelena (1992, s. v. eta). Para Azkue (1969a, s. v. ta), eta sería variante eufónica de ta cuando va precedida de consonante continua: $-l,-n,-r,-s,-z$; pero hoy en día los estudiosos coinciden en considerar eta la forma general y primigenia, siendo ta una variante reducida empleada especialmente tras vocal (Trask 2008, s. v. eta) y utilizada en los dialectos occidentales desde los primeros textos, mientras que en el norte solo pasado el siglo XVIII. En cualquier caso, eta - ta alternan desde fecha temprana (siglos XVI-XVII), cosa que no ocurre con edo-do. Todos estos hechos fónicos llevan a descartar que el castellano norteño do sea un préstamo del euskera edo, como podría pensarse en un principio dada la vitalidad del coordinador vasco y al carácter absolutamente excepcional del elemento romance.

En cuanto a la etimología de edo, no existen hasta el momento verdaderas propuestas; solo se han establecido simples relaciones formales con distintas lenguas, pero sin un contacto lingüístico con el vasco que permita entender el préstamo, más aún teniendo en cuenta que se trata de una palabra gramatical y no léxica. Michelena (1964: 129-130) y con él Trask (2008: s. v. edo) señalan que la semejanza con el antiguo alto alemán eddo 'o' parece ser una coincidencia. Trombetti (1925) lo relaciona con lenguas muy diversas (africana, túrquica, semítica ...), todas, como dicen Agud/Tovar (1991: s. v. edo), hipótesis incomprobables, si bien estos últimos autores no proponen ninguna alternativa. Por su parte, Morvan (2009-2012: s. v.) parece proponer eredu como étimo al considerar edo variante de edu y ésta contracción de eredu.

Un dato que consideramos fundamental, apuntado ya por Azkue (1969b, § 716), es que todos los coordinadores disyuntivos, excepto edo, proceden de otras categorías gramaticales: los adverbios bai, ez, ala, los interrogativos zein y noiz, el numeral bat o los vocablos beste y nai-naiz. No solo sería la única «conjunción» disyuntiva, usado este término como categoría gramatical, sino que, al igual que eta, puede unir cláusulas y sintagmas de cualquier tipo (Euskaltzaindia 1994, 120), rasgos que diferencian a estos dos nexos del resto de coordinadores conjuntivos y disyuntivos.

\footnotetext{
${ }^{27}$ Agradecemos a la Prof. ${ }^{\text {a }}$ Pagola (Universidad de Deusto) la comunicación verbal de este dato.
}

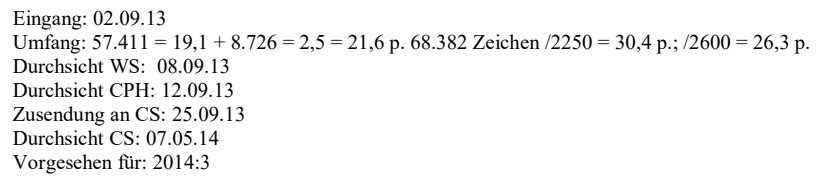


Dejando de lado antiguas propuestas extravagantes que encuentran etimologías en lenguas geográfica y tipológicamente muy distantes del vasco, son mayoría los vascólogos que derivan eta del latín et (con el afijo vasco - $a$, que ninguno explica), ${ }^{28}$ forma esta última que es, además, la que se emplea en los fragmentos en euskera de la carta vasco-navarra de 1415 publicada por Idoate (1969). ${ }^{29}$ Hasta el momento, eta es el único nexo al que los especialistas atribuyen origen latinorománico, pero por todo lo dicho hasta aquí parece claro que edo también lo es. Lo que nos quedaría por dilucidar es si su étimo es el latín et aut o el romance (e)do, dos posibilidades que la fonética dirime a favor del segundo: la sonora $-d$ - del vasco edo apunta sin duda a un étimo romance edo y no a un latino tardío * eto < ET AUT, pues las oclusivas sordas latinas en posición intervocálica se conservaron en vasco sin sonorizar (Michelena 1974, 192s.), como por ejemplo, lat. PECCATU > cast. pecado / eusk. bekhatu. En consecuencia, consideramos que el origen del vasco edo es el castellano edo, que tuvo que pasar al euskera antes de que se produjera la aféresis de la vocal $e$ -

Como trataremos en seguida, esta sucesión de hechos lingüísticos se corresponde perfectamente con lo que conocemos hoy sobre el contacto de lenguas y la jerarquía de préstamos de palabras gramaticales.

\section{Latín et aut $>$ castellano (e)do > vasco edo: conclusiones}

Llegamos a la conclusión de que el pleonasmo latino et aut, cuya existencia y justificación teórica creemos haber demostrado, dio lugar en castellano a un coordinador disyuntivo hasta ahora desconocido, do (tras la aféresis de $e$ - a partir de un primer resultado *edo), que solo hallamos en dos documentos del Monasterio de San Salvador de Oña, al norte de la actual provincia de Burgos, zona limítrofe con el País Vasco que siglos atrás pudo ser territorio de una comunidad bilingüe. En este sentido, quizá resulte significativo que varios de los usos específicos de edo recogidos por

\footnotetext{
${ }^{28}$ Para un breve repaso de las propuestas, cf. Torrens Álvarez $(2013, \S 4)$. Por su parte, Lakarra (2006, 263), aunque no da una etimología concreta, defiende el origen vasco de este nexo, llamando la atención sobre el hecho de que son precisamente las partículas como eta y edo las que tienen una estructura VCV, frente al monosilabismo general CVC de los lexemas del protovasco. En nuestra opinión, postular para los nexos una estructura fónica no solo distinta a la de los lexemas (que pueden constituir palabras sin necesidad de afijo, como en el caso absolutivo), sino más larga (bisílaba), supone una dificultad importante, sobre todo si se tiene en cuenta la tendencia de las lenguas naturales a que las palabras funcionales sean más breves que las de contenido léxico (por ejemplo, Fenk/Fenk-Oczlon 2007, 160).

${ }^{29}$ Michelena (1992, s. v. eta) trae ejemplos de et' seguido de vocal en textos en verso, ya desde Dechepare, pero en la carta de 1415 et, que habremos de interpretar como cultismo, se utiliza ante vocal y ante consonante. En los escritos del s. XVI lo general es eta.
} 
Michelena (1992) son mucho más frecuentes en los autores del sur que en el norte, es decir, tienen mayor extensión en la zona geográfica de contacto más prolongado con el romance. Asimismo, la partícula edota 'o, o bien' < edo + eta es también característica del sur, si bien se documenta escasamente antes del siglo XX.

Mucho se ha escrito sobre el bilingüismo de los territorios vascongados, que en el pasado tuvieron una extensión bastante superior a la actual, al menos hacia el este y sureste, si bien desde la romanización el euskera habría sido la lengua de las áreas rurales y montañosas del interior, mientras que en las ciudades, la lengua de la economía y la administración sería el latín y después el romance castellano, reservándose el euskera para el ámbito familiar. ${ }^{30}$ Un indicio claro de esta diglosia es que el vasco empieza a escribirse muy tarde: testimonios de palabras o frases sueltas existen desde época realmente temprana (pensemos, por ej., en las Glosas Emilianenses), pero los textos redactados íntegramente en euskera hacen su aparición a finales del siglo XV y, sobre todo, a partir del XVI.

Sin duda, y de acuerdo con las jerarquías de préstamos (Moravcsik 1978; Thomason/Kaufman 1988), los elementos vasco-románicos del euskera más numerosos son de naturaleza léxica; no obstante, los trabajos de Matras (1998; 2011, 215ss., entre otros) sobre el contacto de lenguas en la actualidad demuestran que dentro de los elementos funcionales, los conectores ocupan también una posición elevada en la jerarquía de préstamos, y dentro de ellos, los primeros son las expresiones de contraste, según la escala 'but' $>$ 'or' $>$ 'and' (contraste $>$ disyunción $>$ conjunción). Hay lenguas que solo poseen 'and' como expresión propia y que toman 'or' y 'but', o solo uno de ellos, de la lengua o lenguas dominantes con las que están en contacto; otras lenguas carecen incluso de una forma autónoma para expresar 'and', por lo que llegan a importar los tres elementos en diferentes momentos de su historia. ${ }^{31}$ Creemos que este pudo ser el caso del vasco.

La ausencia casi total de testimonios del euskera con anterioridad al siglo XVI dificulta enormemente la reconstrucción de su evolución diacrónica, pero los datos expuestos concuerdan con lo que sabemos sobre las lenguas modernas y con los mecanismos del préstamo lingüístico en

\footnotetext{
${ }^{30}$ Para las diversas cuestiones relativas a la historia externa del euskera, véase, por ejemplo, Zuazo (1995).

${ }^{31}$ El ejemplo del romaní ilustra bien esta situación: «Romani dialects always borrow 'but' from the contemporary or recent contact language (e.g. Slavic no, po and ali/ale, Hungarian de, Turkish ama, Greek ala, German aber). Many Romani dialects also borrow 'or' and 'and'. These latter two are borrowed frequently, but are sometimes retained from an older contact language» (Matras 2011: 217). Para Matras, no hay ninguna razón cultural ni estructural para que 'but' sea más susceptible al préstamo; para él, «The link between contrast and borrowability runs directly via the link between contrasts and a clash between speaker and hearer-sided expectations. In anticipation of the clash, the speaker engages in an increased mental effort to win over the hearer's confidence. It is this increased engagement of the speech production mechanism that (potentially) takes its toll on the ability to effectively manage the selection and inhibition mechanism, increasing the likelihood of selection malfunctions» (218).
} 
lenguas en contacto. La jerarquía 'but' > 'or' > 'and' en los préstamos es necesariamente la inversa, y por ello complementaria, a la expuesta por Haspelmath (2004) y Ohori (2004) sobre la existencia de marcadores específicos en las lenguas naturales, 'and' > 'or' > 'but': muchas lenguas tienen mecanismos propios para la expresión de 'and', pero de estas, algunas no poseen 'or' y son menos las que tienen 'but', por lo que tienden a tomar estos elementos de otras lenguas.

Volviendo al euskera, ya Trask (2008, s. v. eta) dice, como apoyo de la etimología latina de eta, que «is possible, especially since SOV languages often lack a word for 'and' and borrow one». Desconocemos qué mecanismos empleaba el vasco antiguo para expresar los diferentes tipos de coordinación, y aunque es esta materia de la que deberán ocuparse los especialistas en esa lengua, nos atrevemos a proponer que, como palabras gramaticales o funcionales, tomó primeramente et(a) del latín, cuando la - $t$ final todavía se pronunciaba, y tiempo después $e d o$, ya del romance, jerarquía de préstamos que viene avalada por los hechos fónicos. De hecho, creemos que los tres principales coordinadores vascos, eta, edo y ala, ${ }^{32}$ tienen un origen latino-románico, cuestión que desarrollamos en otro trabajo (Torrens Álvarez 2013).

El vasco edo mantuvo su vitalidad hasta hoy, mientras que el castellano (e)do parece que no sobrevivió al siglo XIII. Que el (e)do castellano y su étimo latino fueron formas casi exclusivas de la lengua hablada y probablemente coloquial lo indica su escasísima documentación. No obstante, la demostrada falta de correspondencia entre la oralidad y la escritura en el caso de los coordinadores latinos, que explica el triunfo de $o<$ AUT a pesar del general empleo de $u e l$ en la escritura de todas las épocas - y, lo que es más significativo, de la Plena Edad Media -, ayuda a entender que pudiera existir un pleonasmo latino que, aunque poco atestiguado en los textos, diera lugar al no menos excepcional resultado romance, y que este, sin embargo, tuviera su continuidad en vasco.

Más allá de las conclusiones sobre el proceso diacrónico aquí descrito, lo que hemos visto a propósito de los nexos coordinantes en las tres lenguas pone de manifiesto no solo la inexistencia de una correspondencia biunívoca entre el tipo de relación lógico-semántica y el mecanismo lingüístico empleado (Ohori 2004), sino que las oposiciones conjunción / disyunción y, dentro de esta, inclusión / exclusión entendidas como dicotomías bipolares no permiten dar debidamente cuenta de las relaciones que se pretenden describir. El carácter inherentemente gradual del concepto de coordinación explica en buena medida los fenómenos sincrónicos y diacrónicos que afectan a su codificación lingüística y a su interpretación semántico-pragmática.

${ }^{32}$ Ala provendría del pronombre ál 'otra cosa', 'lo otro, lo demás' < ALID < ALIUD.

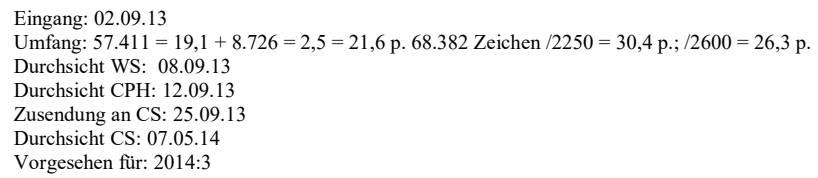




\section{Bibliografía}

Agud, Manuel/Tovar, Antonio, Diccionario etimológico vasco. Materiales para un diccionario etimológico de la lengua vasca, San Sebastián, Diputación Foral de Guipúzcoa, 1991.

Allies, Neil, A history of «uel».From Latin to Castilian, Romania Minor 8 (2008), 73-91.

Andrés Sanz, María Adelaida, drés Sanz (ed.), Isidori Hispalensis episcopi Liber differentiarum [II], Turnhout, Brepols, 2006.

Arbelaiz, Juan José, Las etimologías vascas en la obra de Luis Michelena, Tolosa, Libería Técnica de Difusión, 1978.

Azkue, Resurrección María de, Diccionario vasco-español-francés, Bilbao, La gran enciclopedia vasca, 1969 [19051906] (= 1969a).

Azkue, Resurrección María de, Morfología vasca (Gramática básica dialectal del Euskera), Bilbao, Editorial La gran enciclopedia vasca, 1969 [1923-1925] (=1969b).

Bassols de Climent, Mariano, Sintaxis latina, Madrid, CSIC, 1992.

Bastardas Parera, Juan, Particularidades sintácticas del latín medieval (cartularios españoles de los siglos VIII al XI), Barcelona, Escuela de Filología del CSIC, 1953.

Bonnet, Max, Le latin de Grégoire de Tours, Paris.

Borrego Nieto, Julio, Gramática icónica. Los nexos coordinantes «compuestos» en español, in: Borrego Nieto, Julio, et al. (edd.), Cuestiones de actualidad en lengua española, Salamanca, Ediciones Universidad de Salamanca, 2000, 41-52.

Camacho, José, Algunos problemas de la coordinación disyuntiva en español, in: Martín Vide, Carlos (ed.), Lenguajes naturales y lenguajes formales 2, Barcelona, Universitat de Barcelona, 1990, 411-426.

Camacho, José, La coordinación, in: Bosque, Ignacio/Demonte, Violeta (edd.), Gramática descriptiva del español, vol. 2, Madrid, Espasa Calpe, 1999, 2635-2694.

CODCAR = Sánchez González de Herrero, María Nieves (dir.), Corpus de documentos de la cancillería real castellana (subcorpus electrónico del corpus CHARTA), http://www.bibliateca.es/charta/consultas.php (en prensa).

CODOLGA = Corpus Documentale Latinum Gallaeciae, versión 7 (2010), <http://www.cirp.es/codolga/>.

CORDE = Real Academia Española, Banco de datos (CORDE) [en línea], Corpus diacrónico del español, $<$ http://www.rae.es $>$.

CORHEN = María Jesús Torrens Álvarez (dir.), Corpus Histórico del Español Norteño (subcorpus electrónico del corpus CHARTA), http://www.bibliateca.es/charta/index.html (en prensa).

Corominas, Joan y José Antonio Pascual, Diccionario crítico etimológico castellano e hispánico, Madrid, Gredos, 1980-1991.

Coseriu, Eugenio, Estudios de lingüistica románica, Madrid, Gredos, 1977.

Dik, Simon C., Coordination: Its implications for the Theory of General Linguistics, Amsterdam, North-Holland, 1968.

Du Cange, Charles du Fresne, et al., Glossarium mediae et infimae latinitatis, Niort, Favre, 1883-1887, $<$ http://ducange.enc.sorbonne.fr/>.

eMGH = Monumenta Germaniae Historica, Turnhout, Brepols Publishers, 2011 [DVD].

Ernout, Alfred, Syntaxe latine, Paris, Klincksieck, ${ }^{2} 1964$.

Espinosa Elorza, Rosa, La expresión de la disyunción en castellano medieval: coordinadores discontinuos, in: Alonso, Alegría, et al. (edd.), Actas del III Congreso Internacional de Historia de la Lengua Española, vol. 1, Madrid, Arco/Libros, 1996, 269-279.

Euskalzaindia, Euskal gramatika: lehen urratsak, vol. 4: Juntagailuak, Bilbao, Euskalzaindia, 1994.

Fenk, August/Fenk-Oczlon, Gertraud, Within-Sentence Distribution and Retention of Content Words and Function Words, in: Grzybek, Peter (ed.), Contributions to the Science of Text and Language. Word Length Studies and Related Issues, Dordrecht, Springer, 2007, 157-170.

Fernández Flórez, José Antonio/Herrero de la Fuente, Marta, Colección documental de Otero de las Dueñas, León, Centro de Estudios e Investigación «San Isidoro»/Caja España de Inversiones/Archivo Histórico Diocesano, 1999.

Fontaine, Jacques (ed.), Isidore de Seville, Traité de la nature, Bordeaux, Féret et fils, 1960.

Fornés Guardia, Mercedes, Sobre el paradigma de formas que expresan disyunción en español, Anuario de estudios filológicos 17 (1994), 133-150. 
Fukasawa, Mitsuyo, La coordinación disyuntiva en español: aspecto sincrónico, Revista del Instituto de Lengua y Cultura Españolas 1 (1985), 47-81, 223-268; 2 (1986), 23-53.

Garrido Garrido, José Manuel, Documentación de la Catedral de Burgos (804-1183), Burgos, Garrido Garrido, 1983.

Grice, H. Paul, Logic and conversation, in: id. (1989c), 22-40 (=1989a).

Grice, H. Paul, Further Notes on Logic and Conversation, in: id. (1989c), 41-57 (= 1989b).

Grice, H. Paul, Studies in the way of words, Harvard, Harvard University Press, 1989 (= 1989c).

Hanssen, Federico, Gramática histórica de la lengua castellana, Paris, 1966.

Haspelmath, Martin, Coordinating constructions. An overview, in: id. (ed.), Coordinating constructions, Amsterdam, Benjamins, 2004, 3-40.

Haspelmath, Martin, Coordination, in: Shopen, Timothy (ed.), Language typology and syntactic description, Cambridge, Cambridge University Press, ${ }^{2} 2007,1-51$.

Haugh, Michael, Practices and defaults in interpretating disjunction, in: Jaszczolt, Kasia M./Allan, Keith (edd.), Salience and defaults in utterance processing, Berlin/Boston, De Gruyter Mouton, 2011, 187-225.

Heine, Bernd/Kuteva, Tania, World Lexicon of Grammaticalization, Cambridge, Cambridge University Press, 2002.

Hofmann, Johann Baptist, Lateinische Umgangssprache, Heidelberg, Winter, 1926.

Hualde, José Ignacio/Lakarra, Joseba A./Trask, Robert L., Towards a history of the Basque language, Amsterdam, Benjamins, 1995.

Hualde, José Ignacio/Ortiz de Urbina, Jon, A grammar of Basque, Berlin, Mouton de Gruyter, 2003.

Idoate, Florencio, Una carta del siglo XV en vascuence, Fontes Linguae Vasconum, 2, 1969, 287-288.

Jennings, Ray E., The genealogy of disjunction, New York, Oxford University Press, 1994.

Jennings, Ray E./Hartline, Andrew, Disjunction, in: Zalta, Edward N. (ed.), The Stanford Encyclopedia of Philosophy, Spring 2009 Edition, <http://plato.stanford.edu/archives/spr2009/entries/disjunction/>.

Jiménez Juliá, Tomás, Disyunción exclusiva e inclusiva en español, Verba 13 (1986), 163-179.

Jiménez Juliá, Tomás, La coordinación en español: aspectos teóricos y descriptivos, Verba, Anexo 39 (1995), Santiago de Compostela, Universidade de Santiago de Compostela.

Juret, Abel C., Système de la Syntaxe Latine, Paris, Les Belles Lettres, ${ }^{2} 1933$.

Lakarra, Joseba A., Protovasco, munda y otros: reconstrucción interna y tipología holística diacrónica, Oihenart 21 (2006), 229-322.

LLT-A = Library of Latin Texts, Series A, Turnhout, Brepols Publishers, 2010 [DVD].

Löfstedt, Einar, Philologischer Kommentar zur «Peregrinatio Aetheriae». Untersuchungen zur Geschichte der lateinischen Sprache, Uppsala, Almqvist \& Wiksell, 1911.

Matras, Yaron, Utterance modifiers and universals of grammatical borrowing, Linguistics 36 (1998), 281-331.

Matras, Yaron, Universals of structural borrowing, in: Siemund, Peter (ed.), Linguistic universals and language variation, Berlin, De Gruyter, 2011, 204-236.

Mauri, Caterina, Conjunctive, disjunctive and adversative constructions in Europe: Some areal considerations, in: Ramat, Paolo/Roma, Elisa (edd.), Europe and the Mediterranean as Linguistic Areas. Convergencies from historical and typological perspective, Amsterdam, Benjamins, 2007, 183-214.

Mauri, Caterina, Coordination relations in the languages of Europe and beyond, Berlin/New York, Mouton de Gruyter, 2008.

Mauri, Caterina/van der Auwera, Johan, Connectives, in: Allan, Keith/Jaszczolt, Kasia M. (edd.), The Cambridge Handbook of Pragmatics, Cambridge, Cambridge University Press, 2012, 377-401.

Menéndez Pidal, Ramón, Orígenes del español. Estado lingüístico de la Península Ibérica hasta el siglo XI, Madrid, Espasa-Calpe, 1972 [1926].

Michelena, Luis, Sobre el pasado de la lengua vasca, San Sebastián, Auñamendi, 1964.

Michelena, Luis, El elemento latino-románico en la lengua vasca, Fontes Linguae Vasconum 17 (1974), 183-210 [traducción al inglés: The Latin and Romance Element in Basque, in: Hualde/Lakarra/Trask (1995), 137-170].

Michelena, Luis, Diccionario general vasco / Orotariko euskal hiztegia, Bilbao, Desclée de Brower/Mensajero, 1992.

Moravcsik, Edith A, Language contact, in: J. H. Greenbert (ed.), Universals of human language, Stanford-CA, Standford University Press, 1978, v. 1, 93-122

Morvan, Michel, Dictionnaire étymologique basque en français-espagnol-anglais, 2009-2012, $<$ http://projetbabel.org/basque/dictionnaire.php $>$.

Niermeyer, Jan Frederik, Mediae Latinitatis Lexicon Minus, Leiden, Brill, 1976.

Ohori, Toshio, Coordination in Mentalese, in: Haspelmath, Martin (ed.), Coordinating constructions, Amsterdam, Benjamins, 2004, 41-66. 
Orlandini, Anna, Grammaire Fondamentale du Latin. Négation et argumentation en Latin, vol. 8, Louvain, Peeters, 2001.

Pérez González, Maurilio, El latín de la Cancillería castellana (1158-1214), Salamanca, Ediciones Universidad de Salamanca/Ediciones Universidad de León, 1985.

Politzer, Robert, Synonymic repetition in late Latin and Romance, Language 37 (1961), 484-487.

Riemann, Othon, Syntaxe latine. D’après les principes de la grammaire historique, Paris, C. Klincksieck, 1886.

Riesco, Luis, Las conjunciones «ac», «atque», «et»y «-que» en el epistolario de San Braulio, Habis 2 (1971), $183-198$.

Ruiz Asencio, José Manuel, Colección documental del Archivo de la Catedral de León (775-1230), vol. 4, León, Caja de Ahorros y Monte de Piedad de León, 1989.

Sabbadini, Remigio, L'uso pleonastico delle congiunzioni copulative latine, Rivista di filologia e di istruzione classica 46 (1918), 207-215.

Saralegui, Carmen/Pérez-Salazar, Carmela, Coordinación de sinónimos en textos jurídicos, RILCE. Revista de filología hispánica 8 (1992), 112-133.

Schrijnen, Josef/Mohrmann, Christine, Studien zur Syntax der Briefe des hl. Cyprian, vol. 2, Nijmegen, Dekker \& van de Vegt, 1937.

Stolz, Friedrich/Schmalz, Joseph H., Lateinische Grammatik. Laut- und Formenlehre Syntax und Stylistik, München, Beck, ${ }^{4} 1910$.

Stolz, Friedrich/Schmalz, Joseph H., Lateinische Grammatik. Laut- und Formenlehre Syntax und Stylistik, in fünfter Auflage völlig neu bearbeitet von Manu Leumann und J. B. Hofmann, München, Beck, 1928.

Svennung, Josef, Untersuchungen zu Palladius und zur lateinischen Fach- und Volkssprache, Uppsala, Almqvist \& Wiksells, 1935.

Thomason, Sarah Grey/Kaufman, Terrence, Language contact, creolization, and genetics linguistics, Berkeley/Los Ángeles/Oxford, University of California Press, 1988.

TLL = Thesaurus linguae latinae, editus auctoritate et consilio Academiarum Quinque Germanicarum (Berolinensis, Gottingensis, Lipsiensis, Monacensis, Vindobonensis), Leipzig, Teubner, 1900-1906.

Torrens Álvarez, María Jesús, Nuevas propuestas etimológicas: coordinadores vascos de origen latino-románico, Oihenart 28 (en prensa).

Tovar, Antonio, Gramática histórica latina. Sintaxis, Madrid, Aguirre, 1946.

Trask, Robert L., Etymological Dictionary of Basque, edited for web publication by Max W. Wheeler, University of Sussex, 2008, <http://cryptm.org/ nort/linguistics/Basque\%20etymology.pdf $>$.

Trombetti, Alfredo, Le origini della lingua basca, Memorie della Reale Accademia delle Scienze dell'Istituto di Bologna, Bologna, Azzoguidi, 1925 [Le origini della lingua basca, con le postille autografe dell'autore, reimpr. con introd. de Carlo Tagliavini, Bologna, Forni, 1966].

Villasante, Luis, Sintaxis de la oración compuesta, Oñate, Editorial franciscana Aranzazu, 1979.

Zuazo, Koldo, The Basque Country and the Basque Language. An overview of the external history of the Basque language, in: Hualde/Lakarra/Trask (1995), 5-30. 